\title{
Maternal Serum Matrix Metalloproteinase 14 (MMP14) in Early Onset Preeclampsia and Normal Pregnancy
}

\author{
H Sumawan $^{1 *}$, Sutrisno ${ }^{1}$ \\ ${ }^{1}$ Medical Faculty, Jenderal Soedirman University, Purwokerto, Indonesia
}

\begin{abstract}
Matrix Metalloproteinases 14 presumably play for cytotrophoblast migration and invasion of the uterine wall and in the remodeling of the spiral arteries in pregnancy. Inadequate trophoblastic invasion leads to an inappropriate vascular remodeling, which generates conditions of hypoxia and increased oxidative stress in the placenta early onset preeclampsia. Therefore, it is particularly important to investigating whether MMP14 altered and can be used as biomarker of preeclampsia. There have been no studies done to measure MMP14 in serum maternal between early onset preeclampsia and normal pregnancy The purpose of this study was to analyse whether maternal serum matrix metalloproteinases 14 levels differ in early onset preeclampsia and uncomplicated pregnancies. This crosssectional study was carried out in 20 subjects with early onset preeclampsia and 20 subjects of normotensive pregnant women range 24 up to 34 weeks of gestation. The study was conducted in Margono Hospital Purwokerto, Indonesia. Level of MMP 14 was measured in maternal serum using an enzyme-linked immunosorbent assay (ELISA). The mean difference was statically analysed by independent samples T-test and ROC curve to determine sensitivity and specificity of MMP 14.Women age, gestational age, parity and body mass index showed a non significant difference between both groups. In this study level MMP 14 in serum was higher in pregnant women with preeclampsia compared to the normotensive ( $266.41 \mathrm{vs} 46.80 \mathrm{pg} / \mathrm{dl}$; $\mathrm{p}<0.00$ ). Moreover, the area under curve of serum MMP 14 was 0.936, standard error $0.043, \mathrm{p}<0.00$. The optimal cut-off value of serum MMP at $110.73 \mathrm{pg} / \mathrm{dl}$ showed a high diagnostic value in preeclampsia with a sensitivity of $90 \%$ and a specificity of $90 \%$. Maternal serum MMP 14 was higher in preeclampsia and the important finding is the MMP 14 probably become a marker to predict early onset preeclampsia.
\end{abstract}

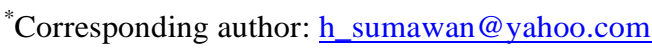




\section{Introduction}

Preeclampsia is a major complication in pregnancy and a leading cause of death and also maternal and perinatal morbidity. Globally, $10-15 \%$ of maternal deaths are directly related to preeclampsia and eclampsia. The incidence of preeclampsia is different in each country, it ranges between 2-8\% of all pregnancy (Duley, 2009). Maternal mortality as reported in East Java as a cause of death by preeclampsia reached 31\% and in Central Java 34\% (Dinas Kesehatan Jawa Tengah, 2016; Dinas Kesehatan Jawa Timur, 2016). Based on the Indonesian Demographic and Health Survey (IDHS) the tendency of maternal mortality increase from 228 per 100,000 live births (2007) to 359 per 100,000 live births in 2012. The Population Survey (SUPAS) reported maternal mortality rate that declined slightly to 305 per 100,000 live births in 2015 (Kementrian Kesehatan, 2017).

Preeclampsia is still described as a "disease of theories" because of the etiology and pathogenesis have not been fully proven. Poor placentation, with shallow remodelling of uteroplacental spiral arteries during the first half of pregnancy had known source of early onset preeclampsia. The ensuing uteroplacental malperfusion, placental oxidative and endoplasmic reticulum stress, then causes placental hypersecretion of pro-inflammatory and antiangiogenic factors into the maternal circulation (Redman C.W.G and Staff A.C., 2018). One of antiangiogenic factors is soluble endoglin (sEng) which has been identified as a central factor to induce endothelium dysfunction of preeclampsia, while its specific mechanism is unclear. Previous studies from laboratory research in trophoblastic BeWo cells found that MMP-14 is the likely cleavage protease of endoglin in the setting of preeclampsia (T. J. Kaitu'u-Lino et al., 2013; T. u. J. Kaitu'u-Lino et al., 2012) MMP-14 has been evidenced in syncitiotrophoblasts, and are known to be downregulated by endothelin1 during first trimester inhibiting trophoblastic migration and invasion (MajaliMartinez A., 2017).

To our knowledge, there is no data on the role of MMP 14 as biomarker for early onset preeclampsia in serum maternal. We aimed in our study to compare MMP 14 levels in women with early onset preeclampsia to corresponding levels in a healthy pregnant control group.

\section{Materials and Methods}

This cross-sectional study was performed between July 2018 and September 2018 after ethical approval by Ethic Committee Medical Faculty Jenderal Soedirman University.

\subsection{Patients.}

The study was undertaken with 20 patients with early onset preeclampsia and 20 normal pregnant women with gestational age between $24-34$ weeks who visit or admitted in Margono Hospital Purwokerto. Written informed consent was obtained from all participants. Preeclampsia was defined as the development of hypertension (systolic blood pressure $(\mathrm{BP}) \geq 140 \mathrm{mmHg}$ and/or diastolic $\mathrm{BP} \geq 90 \mathrm{mmHg}$ on two occasions at least 4 hours apart) and proteinuria ( $\geq 0.3$ grams in a 24 -hour specimen or urine protein/creatinine ratio $(\mathrm{UPCR}) \geq 0.3$ ) after the 20 th week of gestation in a previously normotensive patient. Severe preeclampsia was defined as preeclampsia 
complicated by either a systolic $\mathrm{BP} \geq 160 \mathrm{~mm}$ and/or a diastolic $\mathrm{BP} \geq 110 \mathrm{mmHg}$ (on 2 occasions at least 4 hours apart while the patient was on bed rest) and/or pulmonary edema and/or renal abnormality (progressive renal insufficiency; serum creatinine > $1.1 \mathrm{mg} / \mathrm{dL}$ ) and/or cerebral/visual symptoms (persistent headaches, neurological symptoms, and visual disturbances) and/or hepatic abnormality (severe epigastric or right upper quadrant pain and/or liver transaminases at least twice the normal concentration) and/or platelet count $<100,000 /$ microliter. According to the new preeclampsia criteria, patients with new onset hypertension ( $B P \geq 140 / 90)$ without proteinuria were accepted to have severe preeclampsia if they had one of the above criteria.(Cunningham FG. et al., 2014) Exclusion criteria included premature rupture of membrane, twin or multiple pregnancies or any evidence of previous medical disease.

\subsection{Laboratory Measurements}

Venous blood samples from patients were obtained to measure serum maternal MMP 14. Participants were asked to collect a urine sample for estimating the level of proteinuria. Blood samples for MMP 14 measurements were collected in serum gel separator tubes and centrifuged for 15 minutes at a speed of $1000 \mathrm{~g}$. Supernatant plasma was removed into polypropylene plastic tubes. Samples were taken and stored at $-80 \circ \mathrm{C}$ until the time of analysis. The concentration of MMP14 in serum was calculated with an enzyme linked immunosorbent assay (ELISA) kit, according to the protocols provided by the manufacturers (Human MMP 14, EIAab Science, Wuhan, China). A Microplate photometer was used for readings at $450 \mathrm{~nm}$. The results were expressed as $\mathrm{pg} / \mathrm{mL}$. This test was conducted at Biomedical laboratory Medical Faculty, Jenderal Soedirman University.

\subsection{Statistical Analysis.}

All variables were expressed as mean \pm SD. $p<0.05$ was considered to be statistically significant. Comparisons between two groups were assessed with Student's unpaired $t$-test and Mann- Whitney test, as appropriate. ROC curve was used to assess predictors of MMP 14 levels.

\section{Result and discussion}

The subject characteristics are presented in Table 1. The age, parity, gestational age and body mass index, of the subjects were higher in women with early preeclampsia than in women with normal pregnancy. As shown in Table 1, the mean concentration of serum MMP 14 was higher in early onset preeclampsia than normal pregnancy $(2.02 \pm 0.99 \mathrm{ng} / \mathrm{mL}$ vs. $3.24 \pm 2.67 \mathrm{ng} / \mathrm{mL} ; \mathrm{p}<0.05)$. A ROC analysis lead to AUC of 0.936 for MMP 14 standard error $0.043, \mathrm{p}<0.00$. The optimal cut-off value of serum MMP at $110.73 \mathrm{pg} / \mathrm{dl}$ showed a high diagnostic value in preeclampsia with a sensitivity of $90 \%$ and a specificity of $90 \%$. 
Table 1. The subject characteristics of the study.

\begin{tabular}{llcc}
\hline & \multicolumn{1}{c}{ Preeclampsia } & Normal Pregnancy & \multirow{2}{*}{ P value } \\
\cline { 2 - 3 } & \multicolumn{1}{c}{ Mean \pm SD } & Mean \pm SD & \\
Age & $32,4(8,0)$ & $29,1(6,0)$ & 0,145 \\
Gestasional & $30,9(2,8)$ & $30,4(3,0)$ & 0,595 \\
Age & & $27,6(4,7)$ & 0,089 \\
BMI & $24,8(5,2)$ & $0,85(0,87)$ & 0,201 \\
Parity & $1,25(1,06)$ & $46,8(39,9)$ & 0,000 \\
MMP 14 & $266,4(135,4)$ & &
\end{tabular}

*p values are obtained by independent t-test.

Large cohort of singleton deliveries in Washington State, USA, concluded that African-American descent, chronic hypertension and congenital anomalies were more strongly associated with very- early-onset pre-eclampsia (delivery before GW 34), while younger maternal age, nulli parity and diabetes mellitus were more associated with late-onset disease (Lisonkova \& Joseph, 2013). That phenomena are the same as the results of the characteristics of the sample obtained. Early onset occurs at a young age and has a history of having children. The pathology of early onset comprises lesions of uteroplacental malperfusion. These are associated with maladaptation of the uteroplacental spiral arteries in early pregnancy (8-18 weeks, poor placentation) such that they are too small and too contractile to sustain the non-pulsatile, high volume, low pressure flow needed by the third trimester placenta. The result is oxidative stress and even infarction that damage placental tissue.(Redman

C.W.G and Staff A.C., 2018) . MMPs and their inhibitors play a major role in trophoblast invasion into the uterine wall. The profound changes in uterine microarchitecture required to transform the spiral vessels and create an optimum environment for embryonic development involve a grounding transformation in which MMPs are essential. This MMPs Probably contribute to the transformation of the 120-140 spiral arteries that are necessary to supply the placenta. (Pollheimer, Fock, \& Knöfler, 2014).

Matrix metalloproteinases (MMPs) comprise a family of 23 zinc and calciumdependent proteases that degrade different components of the extracellular matrix. These enzymes are classified into collagenases, stromelysins, matrilysins, membraneanchored MMPs, and others according to their specific substrate. (Nagase H., 2006). Many previous studies focusing in MMP 2 and MMP 9 and showed altered in women with preeclampsia. It has been reported that MMP-2 plasma levels are elevated in preeclampsia and that this event is mediated by the vascular endothelial growth factor (VEGF), which controls vascular permeability. MMP-2 elevation can be detected from the second trimester onwards in the plasma of women who subsequently develop preeclampsia. MMP-9 increases along both, normal and preeclampsiacomplicated pregnancy, while its inhibitor TIMP-1

increases in preeclamptic vs. normal pregnant women. A significant increase of MMP-9 concentrations in serum from women who subsequently developed preeclampsia can be detected during the first and third trimester of gestation. MMP2/MMP-9 ratio provided better compromise between specificity and sensitivity in distinguishing PE from normal pregnancies, than either of the two MMPs alone (Feng et al., 2017; Palei et al., 2012) . 
MMP 14, also known as MT1 MMP, is localized in invadopodia, a structure at the cellular edge of ECM degradation and invasion progression. This MMP expression in cytotrophoblasts is maintained through the first trimester of pregnancy and suggests that, together with its role as pro- MMP2 activator, MMP 14 may be involved in trophoblast invasion. In the present study, we established the normal reference value of the serum concentration of MMP 14 from the second half of pregnancy. We also made two important observations. First, we found that there were women with persistently low MMP 14 levels during the second half of pregnancy would not develop preeclampsia. All sample from normal pregnancy that we measure MMP 14 didn't show both early onset and late onset preeclampsia events. Second, high level of MMP 14, women with early-onset showed almost 5.7 fold than normal pregnancy. AUC value showed 0,93 indicate that this marker probably can be used to predict early onset preeclampsia, which sensitivity and specifity 90 percent. This result suggest that MMP 14 is potential marker to identify or predict the preeclampsia beside MMP 2 and MMP 9.

The previous study demonstrated that MMP-14 is a cleavage protease of endoglin. Alteration endoglin release is associated with the onset of preeclampsia, while the regulatory mechanism is unknown.(Baumann et al., 2008; Hirashima et al., 2008). Endoglin is co-localized with MMP-14 in syncytiotrophoblast cells and is significantly upregulated in placental tissue of patients with preeclampsia (T. J. Kaitu'u-Lino et al., 2013; T. u. J. Kaitu'u-Lino et al., 2012; Zhang XH, 2018). They proposed that MMP-14 cleavage on Endoglin may occur in the maternal-fetal crosssection of the placenta and, then, release its extracellular domain into the maternal circulation to form sEng.(Zhang XH, 2018) This result also showed that MMP 14 not only has high expression in placenta but also release in maternal circulation like soluble endoglin.

Beside some potential result from this research, limited data and sample become shortcoming of our study, and other group like late onset preeclampsia probably can give another comprehensive information related with prediction of preeclampsia.

\section{Conclusion}

Our study demonstrates that the MMP 14 concentration was higher in pregnant women with early onset preeclampsia compared to normal pregnant women. The MMP 14 may play a role as a marker in preeclampsia. There is a need for further studies to clarify the potential role of MMP 14 in early onset and or late onset preeclampsia which has different pathogenesis of preeclampsia and to determine whether it can be regarded as a predictor of the development of preeclampsia.

\section{Conflict of Interests}

The authors report no conflict of interests. The authors alone are responsible for the content and writing of the paper.

\section{Reference}

[1] Baumann, M. U., Bersinger, N. A., Mohaupt, M. G., Raio, L., Gerber, S., \& Surbek, D. V. (2008). First-trimester serum levels of soluble endoglin and 
soluble fms-like tyrosine kinase-1 as first-trimester markers for late-onset preeclampsia. American Journal of Obstetrics \& Gynecology, 199(3), 266.e261266.e266. doi:10.1016/j.ajog.2008.06.069

[2] Cunningham FG., Leveno KJ., Bloom S., Hauth JC., Rouse D., \& Spong C. (2014). Pregnancy Hypertension Williams Obstetrics (Vol. 24th ed, pp. 728). United states of America: Mc Graw Hill Medical Companies.

[3] Dinas Kesehatan Jawa Tengah. (2016). Profil Kesehatan Jawa Tengah, 2015. Retrieved

from http://www.depkes.go.id/resources/download/profil/PROFIL_KES_PROVINSI 2016/13 Jate ng 2016.pdf.

[4] Dinas Kesehatan Jawa Timur. (2016). Profil Kesehatan Jawa Timur, 2015. Retrieved

from http://www.depkes.go.id/resources/download/profil/PROFIL_KES_PROVINSI 2015/15_Jati m_2015.pdf.

[5] Duley, L. (2009). The Global Impact of Pre-eclampsia and Eclampsia. Seminars in Perinatology, 33(3),

doi:https://doi.org/10.1053/j.semperi.2009.02.010

[6] Feng, H., Wang, L., Zhang, M., Zhang, Z., Guo, W., \& Wang, X. (2017). Ratio of matrix metalloproteinase-2 to -9 is a more accurate predictive biomarker in women with suspected pre-eclampsia. Bioscience reports, 37(2), BSR20160508. doi:10.1042/BSR20160508

[7] Hirashima, C., Ohkuchi, A., Matsubara, S., Suzuki, H., Takahashi, K., Usui, R., \& Suzuki, M. (2008). Alteration of Serum Soluble Endoglin Levels after the Onset of Preeclampsia Is More Pronounced in Women with Early-Onset. Hypertension Research, 31, 1541. doi:10.1291/hypres.31.1541

[8] Kaitu'u-Lino, T. J., Tuohey, L., Ye, L., Palmer, K., Skubisz, M., \& Tong, S. (2013). MT- MMPs in pre-eclamptic placenta: Relationship to soluble endoglin production. Placenta, 34(2), 168-173. doi:10.1016/j.placenta.2012.11.034

[9] Kaitu'u-Lino, T. u. J., Palmer, K. R., Whitehead, C. L., Williams, E., Lappas, M., \& Tong, S. (2012). MMP-14 Is Expressed in Preeclamptic Placentas and Mediates Release of Soluble Endoglin. The American Journal of Pathology, $180(3), 888-894$.

doi:10.1016/j.ajpath.2011.11.014

[10] Kementrian Kesehatan. (2017). Profil Kesehatan Indonesia 2016,. Jakarta Retrieved from_http://www.depkes.go.id/resources/download/pusdatin/profilkesehatan-indonesia/Profil- Kesehatan-Indonesia-2016.pdf.

[11] Lisonkova, S., \& Joseph, K. S. (2013). Incidence of preeclampsia: risk factors and outcomes associated with early- versus late-onset disease. American Journal of Obstetrics \& Gynecology, 209(6), 544.e541-544.e512. doi:10.1016/j.ajog.2013.08.019

[12] Majali-Martinez A., V. P., Pollheimer J., Knofler M., Yung H.W., Burton G.J., Tabrizi-Wizsy N.G., Lang U., Hiden U., Desoye G., Dieber-Rotheneder M. . (2017). Endothelin-1 down- regulates matrix metalloproteinase 14 and 15 expression in human first trimester trophoblasts via endothelin receptor type B. Hum. Reprod, 32, 46-54. doi:10.1093/humrep/dew295

[13] Nagase H., V. R., Murphy G. . (2006). Structure and function of matrix metalloproteinases and TIMPs. Cardiovasc. Res., 69, 562-573. doi:10.1016/j.cardiores.2005.12.002

[14] Palei, A. C. T., Sandrim, V. C., Amaral, L. M., Machado, J. S. R., Cavalli, R. C., 
Duarte, G., \& Tanus-Santos, J. E. (2012). Association between matrix metalloproteinase (MMP)-2 polymorphisms and MMP-2 levels in hypertensive disorders of pregnancy. Experimental and Molecular Pathology, 92(2), 217-221. doi:https://doi.org/10.1016/j.yexmp.2012.01.008

[15] Pollheimer, J., Fock, V., \& Knöfler, M. (2014). Review: The ADAM metalloproteinases \&\#x2013; Novel regulators of\&\#xa0;trophoblast invasion? Placenta, 35, S57-S63. doi:10.1016/j.placenta.2013.10.012

[16] Redman C.W.G and Staff A.C. (2018). The Differences Between Early- and Late-Onset Pre- eclampsia. In S. Saito (Ed.), Preeclampsia Basic, Genomic, and Clinical (pp. 157-112): Springer, Singapore.

[17] Zhang XH, Z. H., Lu S, Jiang LL, Wu J, Yang YL, Zhang SA. (2018). MMP-14 aggravates onset of severe preeclampsia by mediating soluble endoglin release. Eur Rev Med Pharmacol Sci, 22(5), 1209-1215. doi:10.26355/eurrev_201803_14460 